Marjeta Česen ${ }^{a, b}$, Marijan Ahel $^{c}$, Senka Terzićc ${ }^{c}$ David Heath ${ }^{a}$, Ester Heath ${ }^{a, b^{*}}$

${ }^{a}$ Department of Environmental Sciences, Jožef Stefan Institute, Jamova cesta 39, 1000

Ljubljana, Slovenia

bJožef Stefan International Postgraduate School, Jamova cesta 39, 1000 Ljubljana, Slovenia

'Division for Marine and Environmental Research, Ruđer Bošković Institute, Division

Bijenička cesta 54, 10000 Zagreb, Croatia

*Corresponding author: Ester Heath, email: ester.heath@ijs.si; telephone +386 1477 3584, address: Jožef Stefan Institute, Jamova 


\section{*Graphical Abstract}
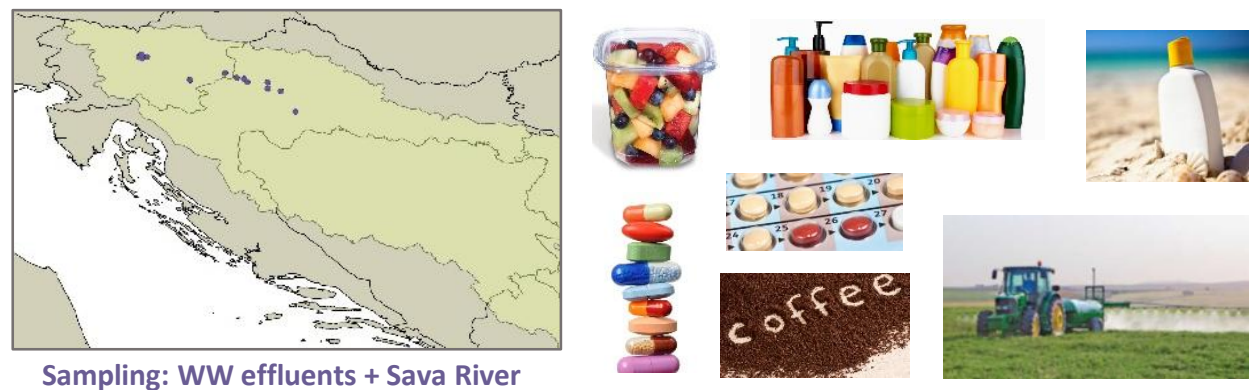

Sampling: WW effluents + Sava River

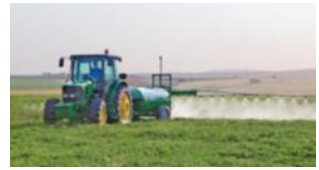


${ }^{*}$ Highlights (for review : 3 to 5 bullet points (maximum 85 characters including spaces per bullet point)

\section{Highlights:}

1. Bisphenols $E$ and $B$ were detected $>L O Q$ in European $S W$ for the first time.

2. Bisphenols $A P, C L 2, P$ and $Z$ were detected $>L O Q$ in European $W W$ for the first time.

3. Correlation between CEC mass loads in Sava River and corresponding WWs was observed.

4. Overall CEC contamination downstream the Sava River was confirmed.

5. All SWs with detected HM-BP, IB or Be-PB posed at least a medium environmental risk. 


\section{THE OCCURRENCE OF CONTAMINANTS OF EMERGING CONCERN IN SLOVENE AND CROATIAN WASTEWATERS AND RECEIVING SAVA RIVER}

Marjeta Česen ${ }^{\mathrm{a}, \mathrm{b}}$, Marijan Ahel $^{\mathrm{c}}$, Senka Terzićc ${ }^{c}$ David Heath, Ester Heath ${ }^{\mathrm{a}, \mathrm{b}^{*}}$

${ }^{a}$ Department of Environmental Sciences, Jožef Stefan Institute, Jamova cesta 39, 1000

Ljubljana, Slovenia

bJožef Stefan International Postgraduate School, Jamova cesta 39, 1000 Ljubljana, Slovenia

'Division for Marine and Environmental Research, Ruđer Bošković Institute, Division

Bijenička cesta 54, 10000 Zagreb, Croatia

*Corresponding author: Ester Heath, email: ester.heath@ijs.si; telephone +38614773584, address: Jožef Stefan Institute, Jamova 39, 1000 Ljubljana, Slovenia

Bisphenol A (BPA), 2-ethylhexyl 4-methoxycinnamate (CNM), 2-hydroxy-4-methoxybenzophenone (HM-BP), 2,2'methylenediphenol (BIS2), 4,4'-biphenol (BP4,4), 4,4'-dihydroxydiphenyl ether (DHDPE), bisphenol AF (BPAF), bisphenol AP (BPAP), bisphenol C (BPC), bisphenol E (BPE), bisphenol F (BPF), bisphenol FL (BPFL), bisphenol M (BPM), bisphenol BP (BPBP), bisphenol P (BPP), bisphenol S (BPS), bisphenol Z (BPZ), 4-cumylphenol (HPP), 2,4-dihydroxybenzophenone (DH-BP), estrone (E1), 17ß-estradiol (E2), 17 $\alpha$-ethynyl estradiol (EE2), CAF, 4-hydroxybenzophenone (H-BP), 2,2'-dihydroxy-4methoxybenzophenone (DHM-BP), clofibric acid (CLA), ibuprofen (IB), naproxen (NP), ketoprofen (KP), diclofenac (DF) and its three transformation products (TPs), diazepam (DZP), methyl paraben (MePB), ethyl paraben (EtPB), propyl paraben (PrPB), butyl paraben (BuPB), iso-butyl paraben (iBuPB), benzyl paraben (BePB), nonylphenol (NONPH) and triclosan (TCS), carbamazepine (CBZ), iso-propyl paraben (iPrPB), bisphenol B (BPB), mecoprop (MEC), bisphenol Cl (BPCL2), bisphenol PH $(B P P H)$, wastewater (WW), wastewater treatment plant (WWTP), surface water (SW), contaminant of emerging concern $(C E C)$, active pharmaceutical ingredients (APIs), personal care products (PCPs), risk quotient (RQ), environmental risk assessment (ERA), transformation products (TPS), solid-phase extraction (SPE), N-methyl-N(trimethylsilyl)trifluoroacetamide (MSTFA), N-(tert-butyldimethylsilyl)-N-methyltrifluoroacetamide with $1 \%$ tertbutyldimethylchlorosilane (MTBSTFA with 1\% TBDMCS), Predicted No-Effect Concentration (PNEC), assessment factor (AF), 
which is 1000 in the case of acute toxicity. When using the data for chronic toxicity, PNEC derives from the ratio between the No-Effect Concentration (NOEC), detection frequency (DFr), limit of quantification (LOQ)

\section{ABSTRACT}

This study investigated the occurrence of 48 contaminants of emerging concern (CEC) in wastewater effluents from three Slovenian and three Croatian waste water treatment plants (WWTP) representing the major inputs into the upper and middle course of the Sava River and simultaneously in the Sava River itself. Two sampling campaigns were carried out in May and July 2017. Samples were extracted using SPE and analysed by GC-MS. In effluents, 23 CEC were $>$ LOQ with caffeine $\left(<49,600 \mathrm{ng} \mathrm{L}^{-1}\right)$ and the UV-filter 4-hydroxybenzophenone $(\mathrm{H}$ $\mathrm{BP},<28,900 \mathrm{ng} \mathrm{L}^{-1}$ ) present in the highest concentrations and being most frequently detected (DFr > 83.3\%). Bisphenol B and E were detected for the first time in wastewater (WW) from Velika Gorica (May) and Zaprešić (July), respectively. In surface water (SW), 19 CEC were detected $>\mathrm{LOQ}$ with CAF being the most abundant and most frequently detected (DFr $=92.9$ \%). Bisphenols $A P, C L 2, P$ and $Z$ were detected $>L O Q$ for the first time in European $S W$. Active pharmaceutical ingredients (API; naproxen, ketoprofen, carbamazepine and diclofenac; the preservative methyl paraben; CAF and UV-filter HM-BP were the most abundant CEC in SW and WW. An increasing trend in the total CEC load downstream the Sava River was observed, indicating cumulative effects of individual sources along the river. The Croatian Zaprešić, Zagreb and Velika Gorica WWTP effluents contributed the most towards the enhanced loads of the CEC studied probably due to their size (WWTP-ZG) or insufficient treatment efficiency (e.g. mechanical treatment at WWTP-Zaprešić). HM-BP was the only compound found at a levels exhibiting high environmental risk $(R Q=1.13)$ downstream from Ljubljana and Domžale-Kamnik WWTPs. Other SW samples that contained HM-BP, ibuprofen (API) and/or benzyl paraben (preservative) posed a medium risk for the environment. The results suggest the need for further monitoring of CEC in the Sava River Basin.

Keywords: Sava River, contaminants of emerging concern, surface water, wastewater, mass loads, risk assessment

\section{Highlights:}

1. Bisphenols $E$ and $B$ were detected $>L O Q$ in European $S W$ for the first time.

2. Bisphenols $A P, C L 2, P$ and $Z$ were detected $>L O Q$ in European $W W$ for the first time.

3. Correlation between CEC mass loads in Sava River and corresponding WWs was observed. 
4. Overall CEC contamination downstream the Sava River was confirmed.

5. All SWs with detected HM-BP, IB or Be-PB posed at least a medium environmental risk.

1. INTRODUCTION

Contaminants of emerging concern (CEC) occur in the environment on a global scale and encompass active pharmaceutical ingredients (APIs), personal care products (PCPs), life-style compounds like caffeine (CAF) and other substances, that appear in the environment due to human activities and have the potential to harm biota and human population (Sauvé and Desrosiers, 2014). Their widespread occurrence in wastewaters (WWs) and surface waters (SWs) has been continuously reported. In addition, some CEC with known effects on aqueous biota remain recalcitrant during WW treatment and under environmental conditions and new CEC with unknown effects are being reported with time (Bueno et al., 2012; Petrie et al., 2016).

It is hard if not impossible to monitor the presence of all potentially harmful compounds in the environment and even harder to control their release in the environment, e.g. by an appropriate treatment technology of wastewater treatment plants (WWTPs). Therefore, providing data on CEC occurrence is essential and serves as a basis for prioritizing candidates that have to be monitored and consequently regulated in terms of their emission. This has already been done for certain CEC in the EU by establishing the WFD Watch list (CEC that are to be monitored) and Priority list (CEC for which Environmental Quality Standards in SWs have been set) (EU Decision 495/2015; Tousova et al., 2017; Sousa et al., 2018). Additionally, some areas within Europe still remain to be investigated in terms of environmental CEC occurrence. An example is Central and South Europe, where the Sava River, the largest tributary (by flow) of the Danube River flows. The Sava River springs in the Slovenian mountains and flows a distance of $945 \mathrm{~km}$ through Croatia, Bosnia and Herzegovina eventually to join the Danube in Serbia. Since it supplies the groundwater aquifers, which are an important source of potable water for inhabitants living in this area, it is important to monitor its quality especially due to surrounding agricultural and industrial activities (Milačič et al., 2017). There were several attempts so far to perform a comprehensive region-specific prioritization of contaminants in the Sava River, which covered a wide spectrum of possible contaminants (Smital et al., 2013; Tousova et al., 2017), however, given the extremely high number of possible contaminants, the data on numerous CEC are still missing. 
The aim of this study was to collect and analyse SW and WW from WWTPs at locations in Slovenia and Croatia along the Sava River and analyse them for 48 CEC including APIs and their selected transformation products (TPs), preservatives, bisphenol compounds, and estrogenic hormones. In addition, an environmental risk assessment based on the concentrations of CEC detected in Sava River was performed for the first time in the Sava River catchment.

\section{EXPERIMENTAL}

\subsection{Materials for organic analysis}

Information on reagents, solvents and analytical standards of CEC (Table 1) and surrogate standards used for the chemical analysis is given in details Supplementary Information (SI-I).

Table 1: Commercial names and abbreviations used for the studied CEC.

\begin{tabular}{|c|c|}
\hline Commercial name & Abbreviation \\
\hline \multicolumn{2}{|c|}{ EDCs: Bisphenols and related compounds, estrogens } \\
\hline Bisphenol A & BPA \\
\hline Bisphenol AF & BPAF \\
\hline Bisphenol AP & BPAP \\
\hline Bisphenol B & BPB \\
\hline Bisphenol BP & BPBP \\
\hline Bisphenol C & BPC \\
\hline Bisphenol Cl & BPCL2 \\
\hline Bisphenol E & BPE \\
\hline Bisphenol F & BPF \\
\hline Bisphenol FL & BPFL \\
\hline Bisphenol M & BPM \\
\hline Bisphenol P & BPP \\
\hline Bisphenol PH & $\mathrm{BPPH}$ \\
\hline Bisphenol S & BPS \\
\hline Bisphenol Z & BPZ \\
\hline 4,4'-biphenol & BP4,4 \\
\hline 2,2'-methylenediphenol & BIS2 \\
\hline 4,4'-dihydroxydiphenyl ether & DHDPE \\
\hline 4-cumylphenol & HPP \\
\hline 4-nonyl-phenol & NONPH \\
\hline Estrone & E1 \\
\hline $17 \beta$-estradiol & E2 \\
\hline $17 \alpha$-ethynyl estradiol & EE2 \\
\hline \multicolumn{2}{|c|}{ UV-filters: benzophenons and other } \\
\hline 2,4-dihydroxybenzophenone & DH-BP (BP1) \\
\hline 4-hydroxybenzophenone & $\mathrm{H}-\mathrm{BP}$ \\
\hline Oxybenzone & HM-BP (BP3) \\
\hline
\end{tabular}




\begin{tabular}{|c|c|}
\hline Dioxybenzone & DHM-BP (BP8) \\
\hline 2-ethylhexyl 4-methoxycinnamate & CNM \\
\hline \multicolumn{2}{|l|}{ APIs and metabolites/TPs } \\
\hline Carbamazepine & CBZ \\
\hline Clofibric acid & CLA \\
\hline Diazepam & DZP \\
\hline Diclofenac as sodium salt & DF \\
\hline 2-[(2,6-Dichlorophenyl)amino]-5-nitrophenyl-acetic acid & DFtp1 \\
\hline 2-anilinophenylacetic acid & DFtp2 \\
\hline 2-[(2-Chlorophenyl)amino]-benzaldehyde & DFtp3 \\
\hline Ibuprofen & IB \\
\hline Ketoprofen & KP \\
\hline Naproxen & NP \\
\hline \multicolumn{2}{|l|}{ Preservatives } \\
\hline Methyl paraben & MePB \\
\hline Ethyl paraben & EtPB \\
\hline Propyl paraben & PrPB \\
\hline Iso-Propyl paraben & IPrPB \\
\hline Butyl paraben & BuPB \\
\hline Iso-Butyl paraben & IBuPB \\
\hline Benzyl-paraben & $\mathrm{BePB}$ \\
\hline Irgasan, triclosan & TCS \\
\hline \multicolumn{2}{|l|}{ Other compounds } \\
\hline Caffeine & CAF \\
\hline Mecoprop & MEC \\
\hline
\end{tabular}

\section{$115 \quad 2.2$ Sampling}

116 Samples of wastewater (WW) effluent from three Slovenian and three Croatian WWTPs

117 were collected during a dry period on two occasions (23 $3^{\text {rd }}$ May and $12^{\text {th }}$ July 2017). The WWTPs differ in their sizes (population equivalents; P.E.), treatment technology, type of receiving WW and daily flow rates (Table 2). Additional information on each WWTP is given in the SI-II.

Table 2: Characteristics of the studied Slovene and Croatian WWTPs.

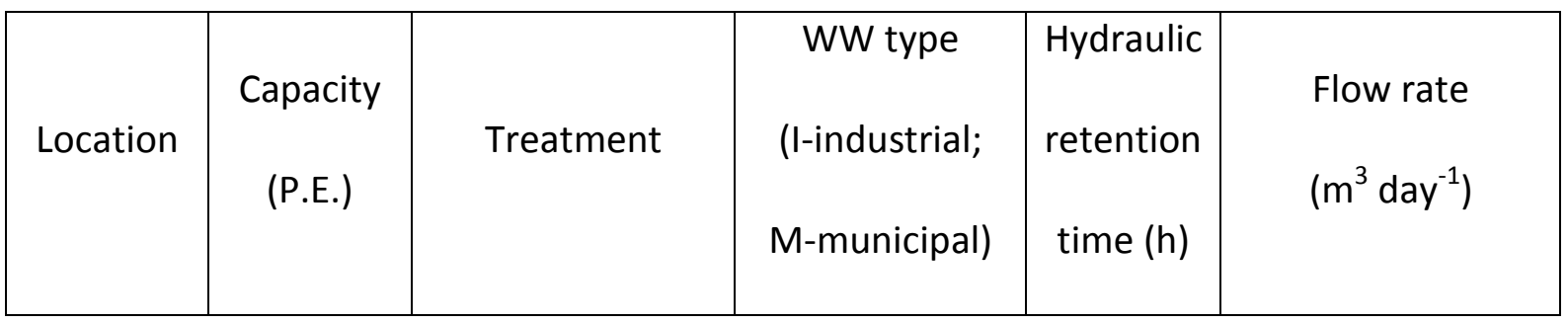




\begin{tabular}{|c|c|c|c|c|c|c|}
\hline \multirow[b]{2}{*}{$\begin{array}{l}\text { Ljubljana } \\
\text { (LJ) }\end{array}$} & \multirow[b]{2}{*}{360,000} & \multirow{2}{*}{$\begin{array}{l}\text { Mechanical- } \\
\text { biological } \\
\text { (suspended } \\
\text { biomass) }\end{array}$} & \multirow[b]{2}{*}{ 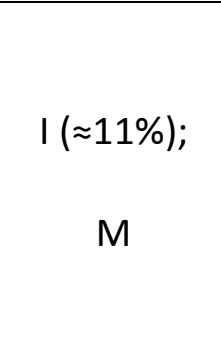 } & \multirow[b]{2}{*}{18} & May & 66,994 \\
\hline & & & & & July & 69,916 \\
\hline Domžale- & & \multirow{2}{*}{$\begin{array}{c}\text { Mechanical- } \\
\text { biological (SBR) }\end{array}$} & \multirow{2}{*}{$\begin{array}{c}\text { I ( } \approx 11 \%) \\
M\end{array}$} & \multirow[b]{2}{*}{16} & May & 17,935 \\
\hline $\begin{array}{l}\text { Kamnik } \\
\text { (DK) }\end{array}$ & 149,000 & & & & July & 18,240 \\
\hline Novo & & Mechanical- & \multirow{2}{*}{$\begin{array}{c}\text { I ( } \approx 12 \%) \\
\text { M }\end{array}$} & \multirow[b]{2}{*}{22} & May & 4,636 \\
\hline $\begin{array}{l}\text { mesto } \\
\text { (NM) }\end{array}$ & 55,000 & $\begin{array}{c}\text { biological } \\
\text { (ultrafiltration) }\end{array}$ & & & July & 4,337 \\
\hline \multirow[t]{2}{*}{ Zaprešić } & \multirow[t]{2}{*}{60,000} & \multirow[t]{2}{*}{ Mechanical } & \multirow[t]{2}{*}{$\mathrm{I}(\approx 38 \%) ; \mathrm{M}$} & \multirow[t]{2}{*}{24} & May & 6,665 \\
\hline & & & & & July & 5,789 \\
\hline \multirow{2}{*}{$\begin{array}{l}\text { Zagreb } \\
\text { (ZG) }\end{array}$} & \multirow[b]{2}{*}{$1,200,000$} & \multirow{2}{*}{$\begin{array}{c}\text { Mechanical- } \\
\text { biological } \\
\text { (activated sludge) }\end{array}$} & \multirow[b]{2}{*}{ I; M } & \multirow[b]{2}{*}{$10-12$} & May & 261,126 \\
\hline & & & & & July & 234,177 \\
\hline \multirow{2}{*}{$\begin{array}{l}\text { Velika } \\
\text { Gorica }\end{array}$} & \multirow[t]{2}{*}{35,000} & \multirow{2}{*}{$\begin{array}{l}\text { Mechanical- } \\
\text { biological } \\
\text { (activated sludge) }\end{array}$} & \multirow[b]{2}{*}{$M$} & \multirow[b]{2}{*}{20} & May & 6,610 \\
\hline & & & & & July & 5,928 \\
\hline
\end{tabular}

123 With the exception of grab WW samples from WWTP-DK (in May), WWTP-ZG (in July) and Zaprešić (May and July), all samples were collected as $24 \mathrm{~h}$ time-proportional samples.

125 The Sava River prior or after WW discharges was also sampled at seven locations (three in 126 Slovenia and four in Croatia) on the same day as the equivalent WW samples (Table 2). The 127 Slovene samples were collected prior to WWTP-L discharge (Ljubljana), after WWTP-LJ and 128 WWTP-DK discharge (Jevnica) and prior to Krka River tributary, into which the WWTP-NM discharges its effluent (Brežice). The First Croatian sample was collected after the Krka River 
130 tributary (Otok Samoborski), the second after the discharge point of WWTP-Zaprešić and 131 Krapina River tributary (Jankomir), the third after WWTPs ZG and Velika Gorica discharge 132 points (Oborovo) and the fourth after the city of Sisak and tributary of Kolpa River (Crnac). 133 All SWs were collected as a grab samples. The daily flows of Sava River used for mass load 134 calculations are given in SI-II. 


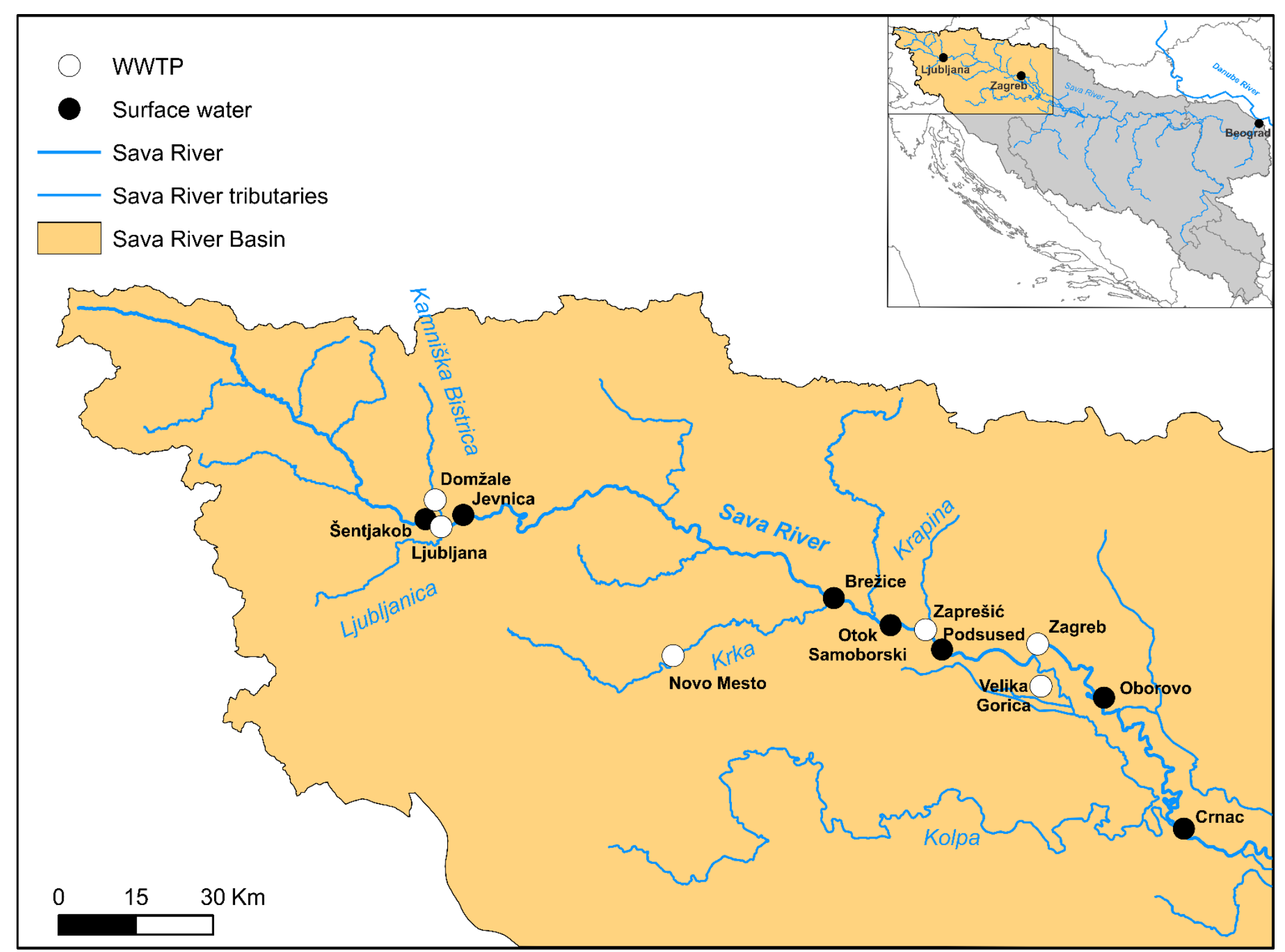

Figure 1: Sampling locations on Sava River (2-column fitting image). 
All samples were filtered through a glass-microfiber (Machery Nagel, Düeren, Germany) and a cellulose nitrate membrane filter $(0.45 \mu \mathrm{m}$; Sartorius Stedim Biotech $\mathrm{GmbH}$, Göttingen, Germany) and stored at $-20^{\circ} \mathrm{C}$ prior to analysis.

\subsection{Sample preparation and analysis}

Table 3 shows the procedure of solid-phase extraction (SPE). Each SW and WW sample was preconcentrated using an Oasis HLB Prime cartridge (Waters, Massachusetts, USA). After loading, the sorbent was washed and/or dried under vacuum (-10 mm Hg, $20 \mathrm{~min}$ ) and eluted with the optimal solution (Table 3). The solvent was evaporated under nitrogen prior to derivatization.

Table 3: SPE conditions for SW and WW analysis.

\begin{tabular}{|c|c|}
\hline SW ( $\left.\mathbf{V}_{\text {sample }}=\mathbf{4 0 0} \mathbf{~ m L}\right)$ & WW $\left(\mathbf{V}_{\text {sample }}=\mathbf{3 0 0} \mathbf{~ m L}\right)$ \\
\hline Filtration (glass-microfibre and $0.45 \mu \mathrm{m}$ cellulose nitrate filter) \\
\hline \multicolumn{2}{|c|}{ Acidification with hydrochloric acid $(\mathrm{pH}=2)$} \\
\hline \multicolumn{2}{|c|}{ Loading $\left(\approx 5 \mathrm{~mL} \mathrm{~min}^{-1}\right)$} \\
\hline$/$ & Wash: $3 \mathrm{~mL}$ of $5 \%$ \\
\hline & methanol/water \\
\hline Elution: $1,800 \mu \mathrm{L}$ of $5 \%$ formic & Elution: $1,800 \mu \mathrm{L}$ of $5 \%$ \\
& ammonia/methanol \\
\hline
\end{tabular}

147 The dried extracts were then halved (Group A: CAF, HPP, NONPH, BIS2, BPAF, DFtp3, H-BP, 148 HM-BP, DHDPE, DH-BP, BP4,4, BPF, BPE, BPA, DHM-BP, BPC, BPB, CNM, BPCL2, BPZ, E1, BPS, 149 E2, BPAP, EE2, BPM, BPP, BPBP, BPPH, BPFL; Group B: MePB, CLA, EtPB, iPrPB, IB, MEC, PrPB, 150 iBuPB, BuPB, DFtp1, NP, TCS, KP, BePB, DZP, CBZ, DF, DFtp2). Group A was derivatized with $15150 \mu \mathrm{L} \mathrm{N}$-methyl-N-(trimethylsilyl)trifluoroacetamide (MSTFA) in $50 \mu \mathrm{L}$ pyridine at $60^{\circ} \mathrm{C}$ for 1 h, whereas Group B was silylated with $30 \mu \mathrm{L} \quad \mathrm{N}$-(tert-butyldimethylsilyl)-Nmethyltrifluoroacetamide with $1 \%$ tert-butyldimethylchlorosilane (MTBSTFA with $1 \%$ TBDMCS) in $70 \mu \mathrm{L}$ ethyl acetate at $60^{\circ} \mathrm{C}$ for $16 \mathrm{~h}$. Samples were analysed using GC-MS 
155

(Agilent 7890B/5977A, USA). Separation was achieved on a DB-5 MS capillary column (30 m $\times 0.25 \mathrm{~mm} \times 0.25 \mu \mathrm{m}$; Agilent, USA) with helium as the carrier gas $\left(1 \mathrm{ml} \mathrm{min}^{-1}\right)$. Each sample $(1 \mu \mathrm{L})$ was injected in the splitless mode at $250^{\circ} \mathrm{C}$. Two different oven programs were used to give optimal chromatographic separation of compounds. For Group A from an initial temperature $65^{\circ} \mathrm{C}$ (held $2 \mathrm{~min}$ ), the oven was ramped at $30{ }^{\circ} \mathrm{C} \mathrm{min}-1$ to $100{ }^{\circ} \mathrm{C}$ (held $2 \mathrm{~min}$ ), then at $10{ }^{\circ} \mathrm{C} \mathrm{min}-1$ to $200{ }^{\circ} \mathrm{C}(2 \mathrm{~min})$, at $10{ }^{\circ} \mathrm{C} \mathrm{min}{ }^{-1}$ to $280{ }^{\circ} \mathrm{C}(10 \mathrm{~min})$ and finally at $30{ }^{\circ} \mathrm{C}$ $\mathrm{min}^{-1}$ to $300{ }^{\circ} \mathrm{C}$ (3.5 min). Total GC-MS runtime was $39.3 \mathrm{~min}$. For Group B, the initial oven temperature was set to $65^{\circ} \mathrm{C}$ for $2 \mathrm{~min}$, then ramped at $30{ }^{\circ} \mathrm{C} \mathrm{min}-1$ to $100{ }^{\circ} \mathrm{C}(2 \mathrm{~min})$, at 10 ${ }^{\circ} \mathrm{C} \mathrm{min}-1$ to $200{ }^{\circ} \mathrm{C}\left(2 \mathrm{~min}\right.$ ), at $10^{\circ} \mathrm{C} \mathrm{min}-1$ to $280^{\circ} \mathrm{C}(2 \mathrm{~min})$ and finally at $30^{\circ} \mathrm{C} \mathrm{min}-1$ to 300 ${ }^{\circ} \mathrm{C}$ (5 min). Total GC-MS runtime was $32.8 \mathrm{~min}$. Additional details of the chemical analysis and method validation are given elsewhere (Česen et al., 2018).

\subsection{Environmental risk assessment}

Environmental risk assessment (ERA) was assessed by determining the risk quotient (RQ) using the following equation:

$$
R Q=\frac{M E C}{P N E C}
$$

where MEC represents the average concentration (RQs were calculated for the SW data). The Predicted No-Effect Concentration (PNEC) was calculated by dividing the compoundspecific $\mathrm{EC}_{50} / \mathrm{LC}_{50}$ values with the assessment factor (AF), which is 1000 in the case of acute toxicity. When using the data for chronic toxicity, the PNEC (predicted no-effect concentration) is derived from the ratio between the No-Effect Concentration (NOEC) and the AF. When only one NOEC value is available (for one trophic level), an AF of 100 is used, when two NOEC values are available, an AF of 50 is used and when data for all three trophic levels exist, an AF of 10 is applied. A RQ $\geq 1$ indicates a potential "high risk", a value between 0.1 and 1 means a "medium risk" and a RQ between 0.01 and 0.1 means a "low/negligible risk" (Papageorgiou et al., 2016).

\section{RESULTS AND DISCUSSION}

\subsection{CEC occurrence in WWs}


Table 4 gives the average, minimal and maximal values of CEC concentrations in WW samples and their detection frequency (DFr) (individual concentrations are given in SI-III). The variation in concentrations are likely due to the extent of certain CEC used in a given sampling area, the treatment technology and the characteristics of a particular WWTP, which affect CEC removal efficiency. Of the 48 target compounds, 23 were detected in levels above the limit of quantification (LOQ) at least once. Caffeine and H-BP were found in the highest concentrations $\left(49,600 \mathrm{ng} \mathrm{L}^{-1}\right.$ and $28,900 \mathrm{ng} \mathrm{L}^{-1}$, respectively) and the average concentration of $\operatorname{CAF}\left(8,190 \mathrm{ng} \mathrm{L}^{-1}\right)$ was the highest among all of the analytes. The CEC were then divided into 3 groups according to their detection frequency (DFr; Table 4). Caffeine and $\mathrm{H}$-BP had the highest detection frequencies (> 83.3\%), whereas HPP, BPE, BPB and E2 were the least frequently detected (DFr at $8.33 \%$ ).

Table 4: The average, minimum and maximum CEC concentration (>LOQ) and DFr in WW samples.

\begin{tabular}{|l|c|c|c|c|}
\hline \multirow{2}{*}{ CEC } & \multicolumn{2}{|c|}{ Concentration (ng L $\left.{ }^{-1}\right)$} & \multirow{2}{*}{ DFr } \\
\cline { 2 - 4 } & Average & Min. & Max. & \\
\hline CAF & 8,190 & 133 & 49,600 & $100.0 \%$ \\
\hline HPP & 51.9 & 51.9 & 51.9 & $8.33 \%$ \\
\hline BIS2 & 20.4 & 4.94 & 36.4 & $58.3 \%$ \\
\hline BPAF & 1.47 & 0.0367 & 3.40 & $41.7 \%$ \\
\hline H-BP & 3,000 & 7.50 & 29,900 & $83.3 \%$ \\
\hline HM-BP & 15.1 & 2.47 & 48.5 & $50.0 \%$ \\
\hline DH-BP & 306 & 36.1 & 563 & $33.3 \%$ \\
\hline BPF & 44.3 & 2.54 & 117 & $41.7 \%$ \\
\hline BPE & 476 & 476 & 476 & $8.33 \%$ \\
\hline BPA & 971 & 44.3 & 2,620 & $66.7 \%$ \\
\hline BPB & 27.1 & 27.1 & 27. & $8.33 \%$ \\
\hline E1 & 840 & 88.5 & 1,980 & $41.7 \%$ \\
\hline & & & & \\
\hline
\end{tabular}




\begin{tabular}{|l|c|c|c|c|}
\cline { 4 - 5 } EPS & 316 & 108 & 435 & $25.0 \%$ \\
\hline MePB & 713 & 713 & 713 & $8.33 \%$ \\
\hline IB & 379 & 11.8 & 1,910 & $66.7 \%$ \\
\hline MEC & 5,340 & 4,330 & 6,130 & $33.3 \%$ \\
\hline DFtp1 & 38.0 & 8.05 & 67.9 & $16.7 \%$ \\
\hline NP & 966 & 81.6 & 2,190 & $50.0 \%$ \\
\hline KP & 1,210 & 53.8 & 2,460 & $53.8 \%$ \\
\hline Be-PB & 409 & 23.6 & 676 & $28.6 \%$ \\
\hline CBZ & 809 & 86.2 & 5,320 & $75.0 \%$ \\
\hline DF & 480 & 113 & 812 & $70.6 \%$ \\
\hline
\end{tabular}

193 Further, mass loads using determined CEC concentrations were calculated taking into 194 account the daily flow rates at the studied WWTPs (Table 2; SI-III).The Spatial variation in 195 sums of mass loads at Slovene vs. Croatian WWTPs revealed that higher level of 196 contamination derives from the latter for the majority of detected CEC in May (17 out of 22) 197 and in July (16 out of 20; Figure 2). This can be related to either greater use of CEC in Croatia 198 and/or lower removal efficiency of Croatian WWTPs if compared to Slovene WWTPs. Indeed, 199 WWTP-Zaprešić includes only mechanical treatment, whereas WWTP-VG is planned to be reconstructed in the near future due to its current poor biological treatment efficiency (Table 2). 
A

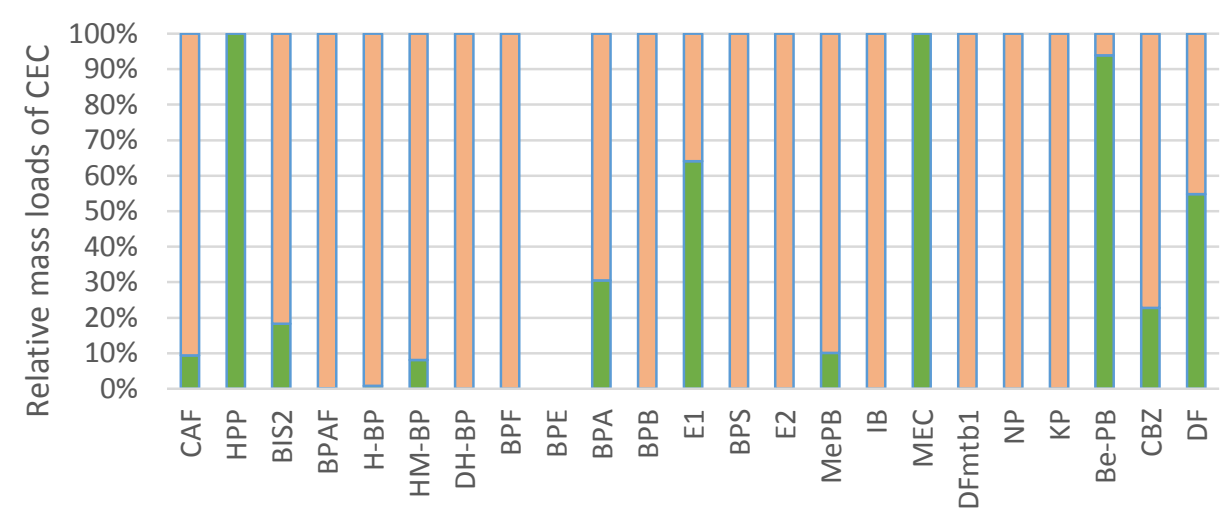

$\square$ Croatian WWTPs

Slovene WWTPS

CEC

B

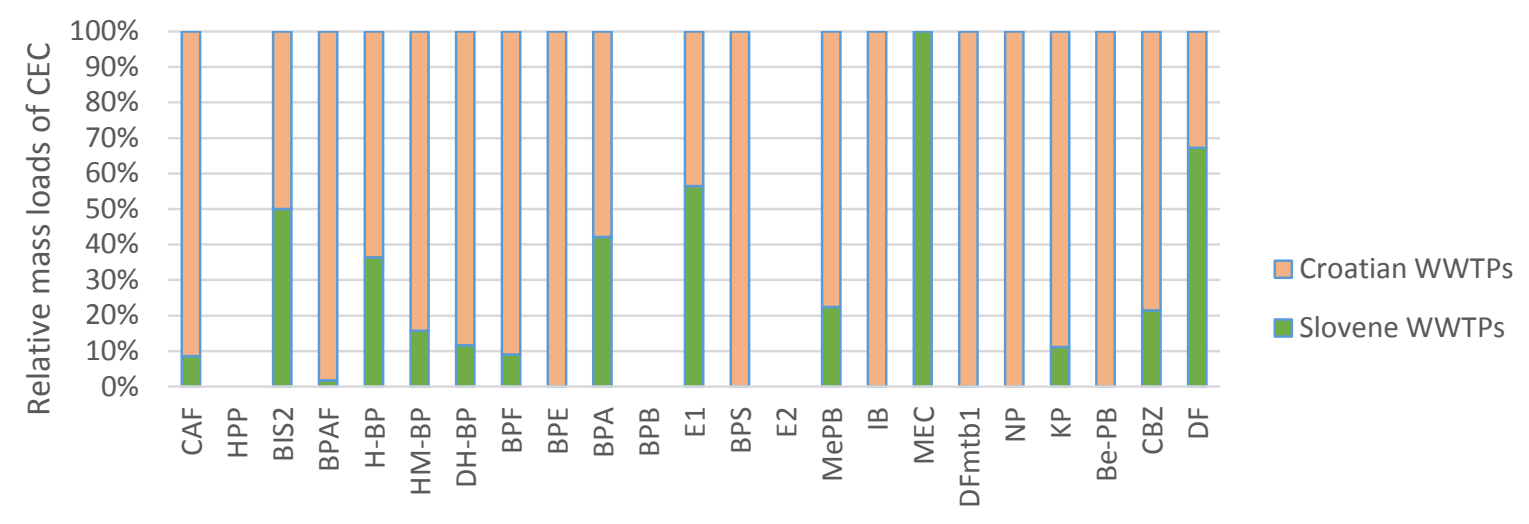

CEC

203

204

205

206

207

208

209

210

211

212

213

214

215

Figure 2: Total CEC mass loads in Slovene and Croatian WWTPs (stacked columns; A = May; B = July) (2column fitting image).

Figure 3 shows the overall CEC contamination from each WWTP in May and in July. The highest amounts of CEC were released from Croatian WWTPs with one exception, i.e. WWTP-L on May had lower total mass load than WWTP-VG (182 $\mathrm{g} \mathrm{day}^{-1}$ vs. $\left.174 \mathrm{~g} \mathrm{day}^{-1}\right)$. The obvious difference in mass loads between the two abovementioned WWTPs (Zaprešić and VG) and Slovene WWTP-NM is also clear despite the fact that they all have comparable sizes and daily flow rates (Table 2). The latter is probably more efficient since advanced biological treatment, i.e. biofiltration, is applied. In fact, for highly biodegradable compounds like e.g. CAF the major factor determining the mass loads in WWTP effluents is not the size of a certain WWTP but rather its removal efficiency.

Additional clear difference in the calculated total mass loads between both capital WWTPs was also observed. In this case it derives from varying sizes of both WWTPs rather than 
removal efficiencies since both apply the mechanical-biological treatment (Table 2; Figure 3). Therefore, higher mass loads of individual CEC were expected and mostly confirmed for WWTP-ZG. Surprisingly, few exceptions were observed, i.e. Be-PB and BPA in May, MePB in July and E1 and DF on both samplings. This could be explained by a significantly higher use and occurrence of these contaminants in Slovene WWs or by a highly inconsistent removal which was already reported in the literature for e.g. DF (Archer et al., 2017).

In particular case of WWTP-Zaprešić, the effluent had considerably higher total mass loads in May (599 $\mathrm{g} \mathrm{day}^{-1}$ ) than July (192 $\mathrm{g} \mathrm{day}^{-1}$; Figure 3). High overall mass load in May mainly origins from the high mass loads of CAF and H-BP, that accounted for $88.5 \%$ of the total mass load (SI-III). CAF was the most abundant also in WWTP-Zaprešić sample from July since it accounted for $53.6 \%$ of overall mass load (SI-III). The opposite phenomenon was revealed in the case of WWTP-VG with higher total mass load observed in July ( $250 \mathrm{~g} \mathrm{day}^{-1}$ vs. $174 \mathrm{~g}$ day $^{-1}$ ), where $57.8 \%$ of the total mass load belonged to CAF. Interestingly, the sample from May contained only $22.5 \mathrm{~g} \mathrm{day}^{-1}$ of CAF, which represents $12.9 \%$ of overall mass load (SI-III).

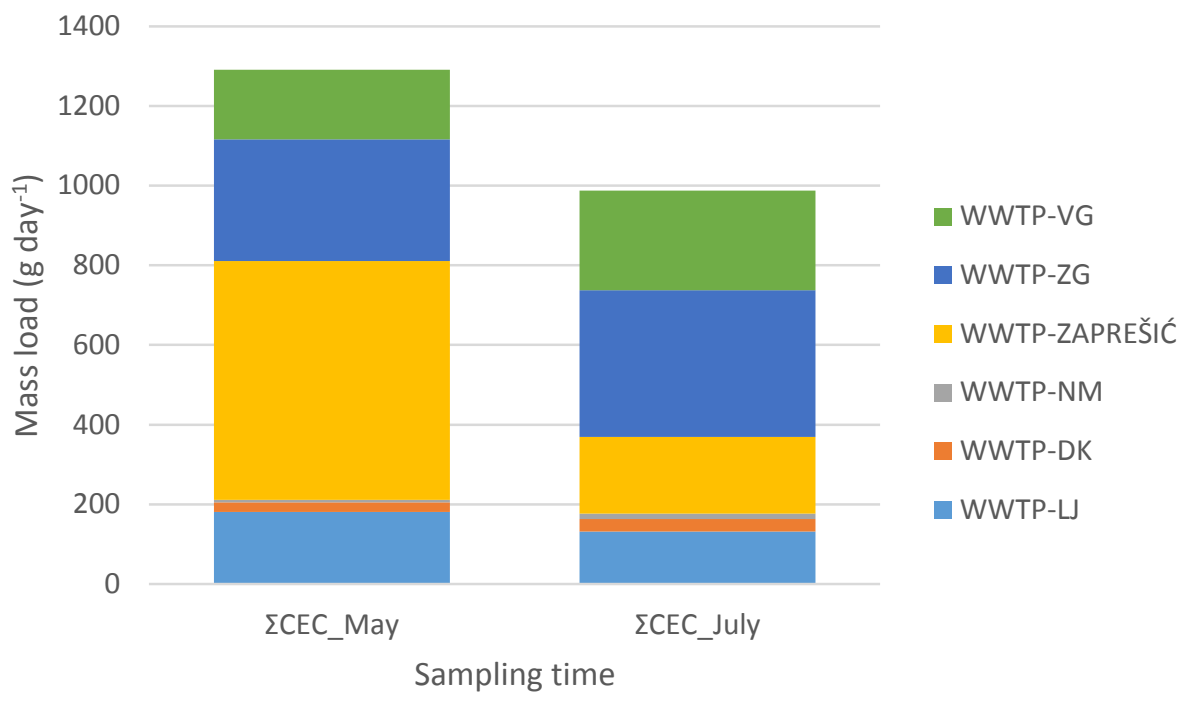

Figure 3: Total mass loads of detected CEC for each WWTP in May and July 2017 (1-column fitting image).

\section{Comparison with the literature data}

The data on detected CEC concentrations was compared with five other studies (SI-IV) including a EU-wide study by Loos et al. (2013), one study of the Western Balkans by Terzić et al. (2008), a Slovene study by Česen et al. (2018), a Spanish study by Osorio et al. (2014) addressing the occurrence of DF TPs and a review paper addressing the occurrence of CEC in 
Table 5: Comparison of average bisphenol concentration (in $\mathrm{ng} \mathrm{L}^{-1}$ ) detected in Slovene and Croatian WWs.

\begin{tabular}{|c|c|c|c|}
\hline \multirow{2}{*}{} & \multicolumn{2}{|l|}{ Average / median concentrations in WW samples - this study } & (Česen et al., 2018) \\
\cline { 2 - 4 } & Slovenia & Croatia & 4.03 \\
\hline BIS2 & $27.1 / 35.6$ & $15.4 / 15.4$ & 2.24 \\
\hline BPAF & $0.0367 / 0.0424$ & $2.43 / 1.95$ & 3.39 \\
\hline BPF & $3.77 / 3.77$ & $71.2 / 58.9$ & $<$ LOQ \\
\hline BPE & $<$ LOQ & $476 / 476$ & 58.7 \\
\hline BPA & $540 / 177$ & $1,690 / 2,340$ & $<$ LOQ \\
\hline BPB & $<$ LOQ & $27.1 / 27.1$ & 28.0 \\
\hline BPS & $<$ LOQ & $316 / 404$ & \\
\hline
\end{tabular}

the UK WWs by Petrie et al. (2015). The findings reveal higher average concentrations of CAF, BIS2, DH-BP, BPF, BPA, E1, BPS, E2, MePB, NP and KP (e.g. up to few orders of magnitude in the case of KP - this study: $1,210 \mathrm{ng} \mathrm{L}^{-1}$; Petrie et al. (2015) > $23.0 \mathrm{ng} \mathrm{L}^{-1}$ ) in the present study. Only IB and DF levels in the UK (Petrie et al., 2015) and MEC and CBZ in EUwide study (Loos et al., 2013) were comparable with the concentrations of CEC detected in Slovenia and Croatia (SI-IV). One TP of DF, namely DFtp1, was present in WWTP-VG1 and WWTP-VG2 at 5,720 $\mathrm{ng} \mathrm{L}^{-1}$ and $781 \mathrm{ng} \mathrm{L}^{-1}$, respectively. These values are considerably higher than the ones found in the literature, i.e. $20.0-29.0 \mathrm{ng} \mathrm{L}^{-1}$ and $<\mathrm{LOQ}-6.64 \mathrm{ng} \mathrm{L}^{-1}$ in Spanish and Slovene effluents, respectively (Osorio et al., 2014; Česen et al., 2018). Interestingly, a comparison with Česen et al. (2018) revealed the presence of similar positive hits for bisphenols, e.g. BIS2, BPAF, BPF, BPA and BPS were detected in both studies, whereas BPE and BPB were detected only in this study. The average concentrations of BIS2, BPF, BPA and BPS were considerably higher in this study (SI-IV). In addition, we calculated average values of bisphenols separately for Slovene and Croatian WW samples. Except for BIS2, all other bisphenols were present in higher concentrations in samples collected at Croatian WWTPs (Table 5). Slovene WW analysed within this study contained higher concentrations of BIS2 and BPA if compared to that reported by Česen et al. (2018). Finally, WW samples contained also higher BPA concentrations than reported by Terzić et al. (2008). 


\subsection{CEC occurrence in SWs}

259 Table 6 gives the average, minimal and maximal concentrations and DFr of CEC in SW (for 260 individual values see SI-V). Out of 48 CEC, 19 were quantified (>LOQ) at least once. Similar to 261 WW, CAF was present in the highest concentrations among all the studied CEC and had the 262 highest average concentration among all of the analysed samples $\left(1,390 \mathrm{ng} \mathrm{L}^{-1}\right.$ and $283 \mathrm{ng} \mathrm{L}^{-}$ $263{ }^{1}$, respectively), followed by Be-PB (457 $\mathrm{ng} \mathrm{L}^{-1}$ and $246 \mathrm{ng} \mathrm{L}^{-1}$, respectively; Table 6). The 264 highest DFr in SW was observed for CAF; the UV-filter HM-BP, the bisphenol BPS, the 265 preservatives MePB, EtPB, PrPB, BePB and the pharmaceuticals NP, KP, and CBZ (> $87.5 \%$ ).

Table 6: The average, lowest and highest CEC concentration (>LOQ) along with DFr in collected SW samples.

\begin{tabular}{|l|c|c|c|c|}
\hline \multirow{2}{*}{ CEC } & \multicolumn{2}{|c|}{ Concentration (ng/L) } & \multirow{2}{*}{ DFr } \\
\cline { 2 - 5 } & Average & Min. & Max. & \\
\hline \multirow{2}{*}{ CAF } & 283 & 37.0 & 1,390 & $92.9 \%$ \\
\hline HM-BP & 9.79 & 2.44 & 17.1 & $14.3 \%$ \\
\hline BPA & 11.3 & 4.48 & 44.2 & $100 \%$ \\
\hline BPCL2 & 61.5 & 1.53 & 215 & $35.7 \%$ \\
\hline BPZ & 0.884 & 0.365 & 2.09 & $71.4 \%$ \\
\hline BPS & 4.68 & 0.250 & 9.11 & $14.3 \%$ \\
\hline BPAP & 9.00 & 1.68 & 35.2 & $85.7 \%$ \\
\hline BPP & 0.704 & 0.540 & 0.903 & $21.4 \%$ \\
\hline MePB & 6.45 & 6.45 & 6.45 & $7.14 \%$ \\
\hline EtPB & 26.3 & 14.8 & 139.50 & $100 \%$ \\
\hline IB & 11.12 & 4.79 & 67.2 & $85.7 \%$ \\
\hline MEC & 46.2 & 1.46 & 262 & $50.0 \%$ \\
\hline & & 10.4 & 10.4 & $7.14 \%$ \\
\hline & & 0.815 & 23.4 & $92.9 \%$ \\
\hline & & & & \\
\hline
\end{tabular}




\begin{tabular}{|l|c|c|c|c|}
\cline { 5 - 5 }$N P$ & 7.95 & 2.67 & 20.4 & $100 \%$ \\
\hline KP & 6.10 & 0.897 & 52.7 & $100 \%$ \\
\hline Be-PB & 246 & 175 & 457 & $100 \%$ \\
\hline CBZ & 8.60 & 2.69 & 18.4 & $100 \%$ \\
\hline DF & 2.30 & 0.0649 & 4.62 & $42.9 \%$ \\
\hline
\end{tabular}

268 Similar to WW, mass loads in SW were calculated using the daily Sava River flows on both 269 sampling campaigns (SI-V). The majority of CEC were more abundant in Croatian samples 270 from May (17 out of 19) and from July (10 out of 15; Figure 4), which might be correlated to 271 the fact that only 3 samples of Sava River were collected in Slovenia, whereas 4 were 272 sampled in Croatia. Regardless, the higher mass loads in Croatia could be also correlated 273 with the findings for WW analysed within this study, where Croatian samples contained 274 higher number of positive hits and CEC mass loads regardless of the sampling time. 
A

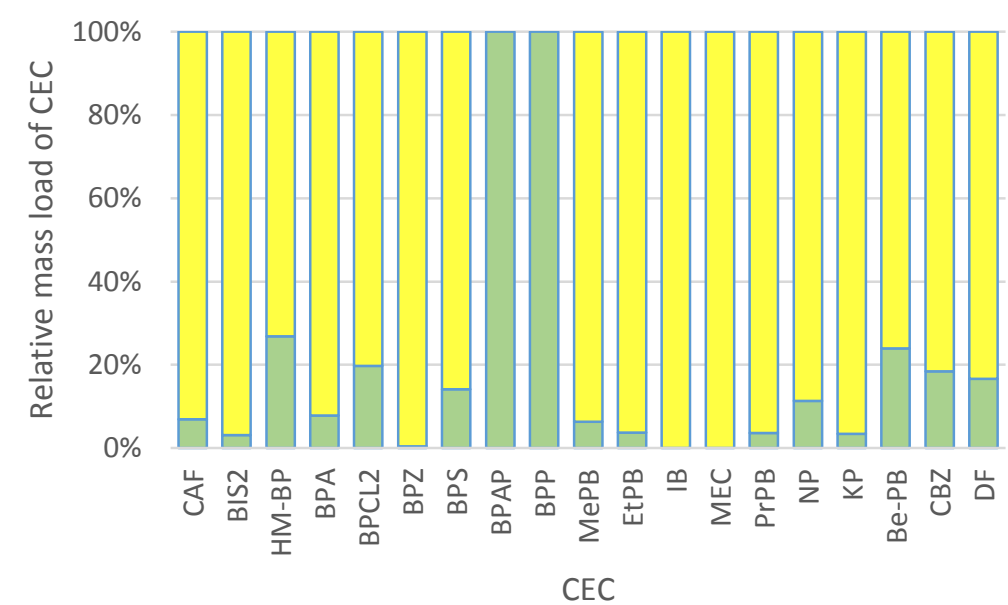

$\square$ Croatia

$\square$ Slovenia

275

B

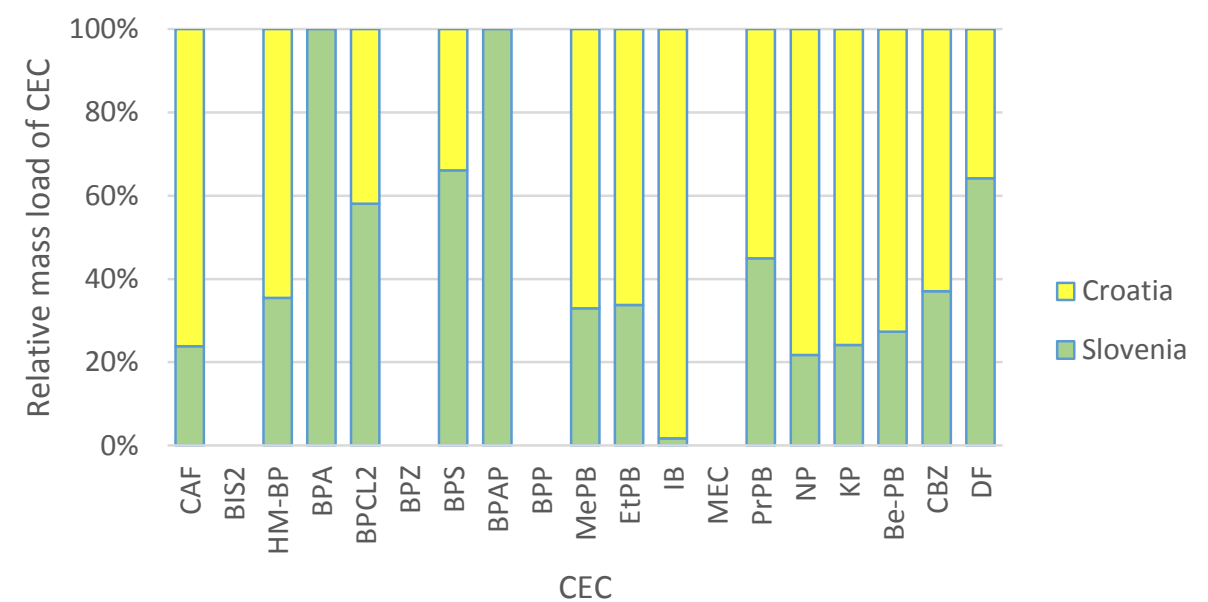

277 Figure 4: CEC mass loads in Slovene and Croatian samples of Sava River (stacked columns; $\mathrm{A}=\mathrm{May}$; $\mathrm{B}=\mathrm{July}$ )

278 (2-column fitting image).

279 In general, total CEC mass loads were slightly higher on May if compared to July, which could 280 be explained by potentially increased environmental degradation (e.g. biodegradation and 281 photolysis) during Summer month (Figure 5). A noteworthy result was observed for sample 282 from Crnac on May, that contained the highest amounts of CEC with CAF (529 mg sec ${ }^{-1}$ ), BPA 283 (81.6 mg sec$\left.{ }^{-1}\right)$, BPP $\left(53.0 \mathrm{mg} \mathrm{sec}^{-1}\right)$, IB $\left(99.4 \mathrm{mg} \mathrm{sec}^{-1}\right)$ and KP $\left(20.0 \mathrm{mg} \mathrm{sec}^{-1}\right)$ being the most 284 abundant. Possible explanation for this deviation is given in section 3.3., where also trend in contamination of Sava River is discussed in details. 


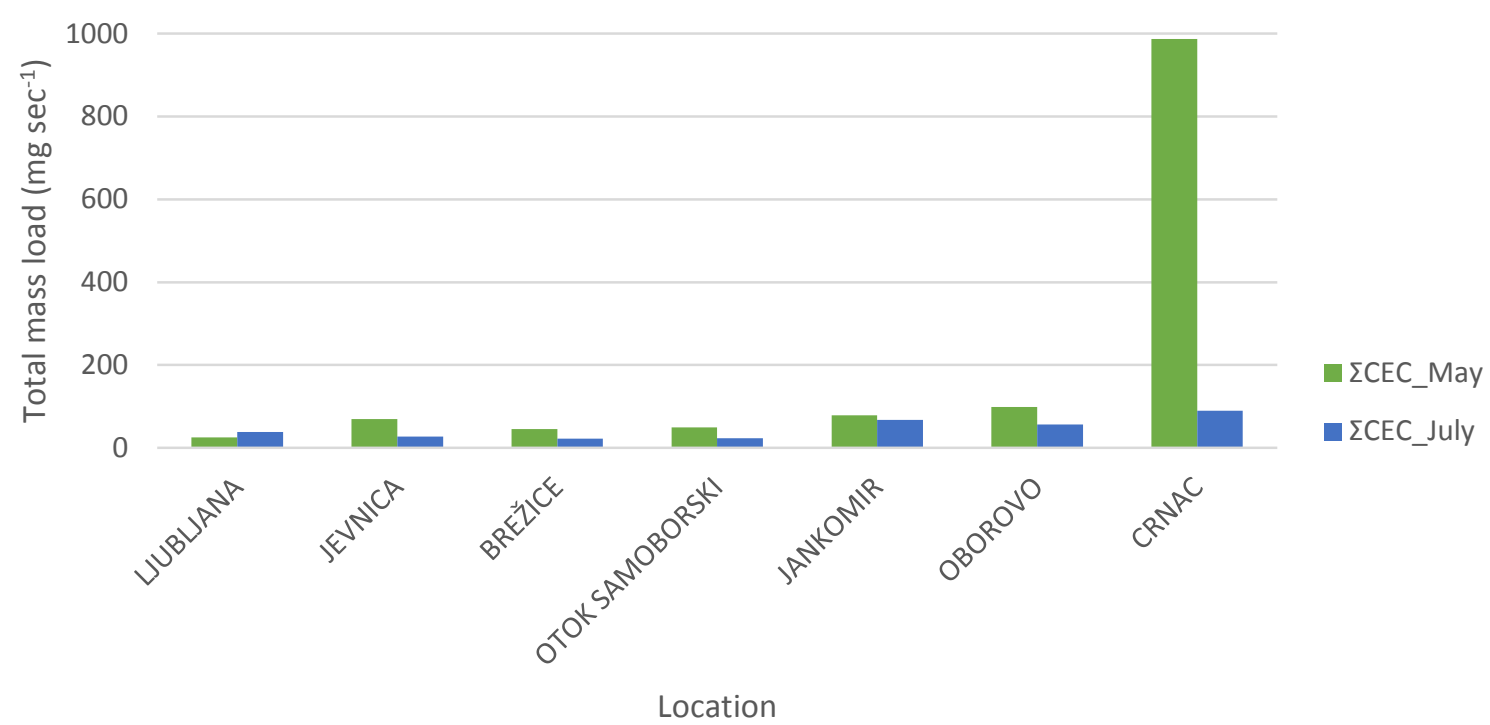

Figure 5: Total mass loads of detected CEC in Sava River in May and July.

\section{Comparison with the literature data}

289 Concentrations in SW were also compared with the available literature data in four publications addressing the same issue in Macedonia, Slovenia, Italy and UK (Meffe and de Bustamante, 2014; Petrie et al., 2015; Stipaničev et al., 2017; Česen et al., 2018). In general, comparable values among all these studies were found for CAF, BIS2, HM-BP, BPS, MePB, EtPB, PrPB, NP, KP and CBZ (SI-IV). DF was the only compound found in lower concentrations within this study (2.30 $\mathrm{ng} \mathrm{L}^{-1}$ ) compared to the others (up to $154 \mathrm{ng} \mathrm{L}^{-1}$; SI-IV). BPA (61.5 ng L' ${ }^{1}$ ) and IB (46.2 $\mathrm{ng} \mathrm{L}^{-1}$ ) were more abundant compared to the Slovene study (BPA: $7.50 \mathrm{ng} \mathrm{L}^{-1}$ $27.9 \mathrm{ng} \mathrm{L^{-1 }}$; IB: $4.07 \mathrm{ng} \mathrm{L}^{-1}-11.6 \mathrm{ng} \mathrm{L}^{-1}$ ), but comparable with all other European studies. Interestingly, BPCL2, BPZ, BPAP, BPP, MEC and Be-PB were > LOQ only in this study, where BPCL2, BPZ, BPAP and BPP were, to the author's knowledge, quantified $\left(0.884 \mathrm{ng} \mathrm{L}^{-1}\right.$ for BPAP to $6.45 \mathrm{ng} \mathrm{L}^{-1}$ for BPP) in European SW for the first time.

\subsection{Trend in CEC mass loads along the Sava River and correlation between SW and WW analysis}

Among all investigated CEC, only CBZ and CAF were detected in all SW and WW samples collected with the absence of CAF in SW sample Otok Samoborski on July as the only exception. The ubiquitous presence of CBZ could be explained by its known poor biodegradation and deconjugation of CBZ metabolites during WW treatment (Archer et al., 2017). On the contrarily, CAF is readily biodegradable (Tran et al., 2018), yet its presence in 
WW and SW can be correlated to the high global consumption of CAF-containing beverages (Gracia-Lor et al., 2017).

Figure 6 shows the total mass loads at each sampling location from Ljubljana prior to WWTP$\mathrm{LJ}$ and WWTP-DK effluents to Crnac as the last sampling point on Sava River (Figure 1). In the case of WWTP-L and WWTP-DK as well as WWTP-ZG and WWTP-VG, the sums of mass loads are given since both pairs of WWTPs influence the corresponding SW Sample, i.e. Jevnica and Oborovo, respectively. Generally, the increasing mass loads were observed for SW samples (blue) downstream Sava River flow for both samplings with the few exceptions. The drop in mass loads between Jevnica and Brežice can be related to possible degradation of CEC in the river itself in this relatively long river section. Additionally, Ljubljana sample from July contained higher mass loads than Jevnica, where WWTP-LJ and WWTP-DK discharges contribute to overall pollution. This can be explained by the fact that CAF was highly abundant in Ljubljana sample, i.e. it represented $53.1 \%$ of total mass load in this sample, whereas in Jevnica sample, CAF accounted only for $16.4 \%$ of total mass load (SI-V). The third exception was observed for a pair of samples from Jankomir and Oborovo on July, where higher mass load in Jankomir can be also related to a higher BePB abundance, i.e. $66.2 \%$ vs. only $32.7 \%$ in a sample from Oborovo.

In general, relatively constant increase in CEC contamination downstream Sava river can be correlated to the calculated mass loads coming from the studied WWTPs despite their varying inputs (from $6.83 \mathrm{~g} \mathrm{day}^{-1}$ for WWTP-NM in May to $619 \mathrm{~g} \mathrm{day}^{-1}$ for WWTPs ZG and VG in July; Figure 6). The significantly higher increase was observed among the last two Sava River samples, i.e. Oborovo and Crnac especially in May.

The reason for such an increase derives from the additional inputs of the Kupa River and the city of Sisak prior to the Crnac sampling location. Higher increase than expected, could be a consequence of the fact that the sampling point at Crnac was possibly situated before the full mixing of wastewaters of the nearby city of Sisak with main flow of the Sava River. 
A

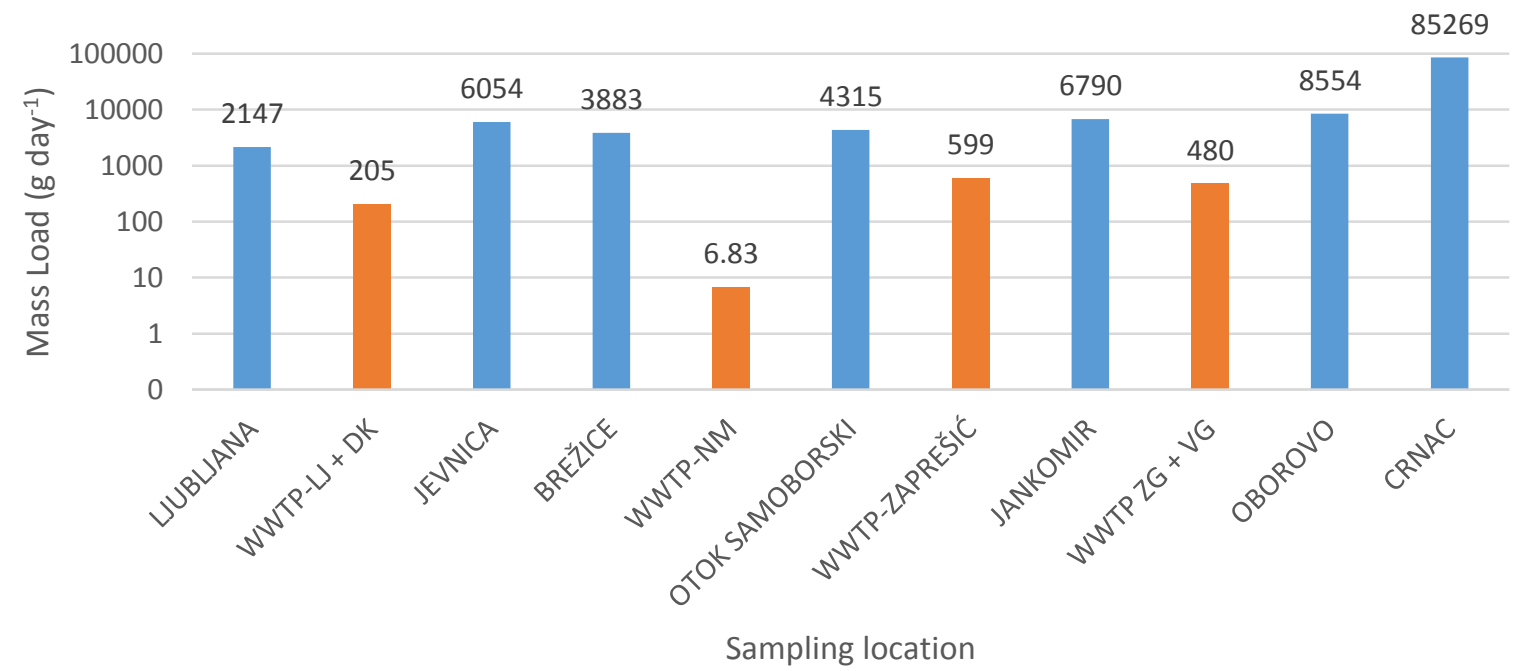

333

B

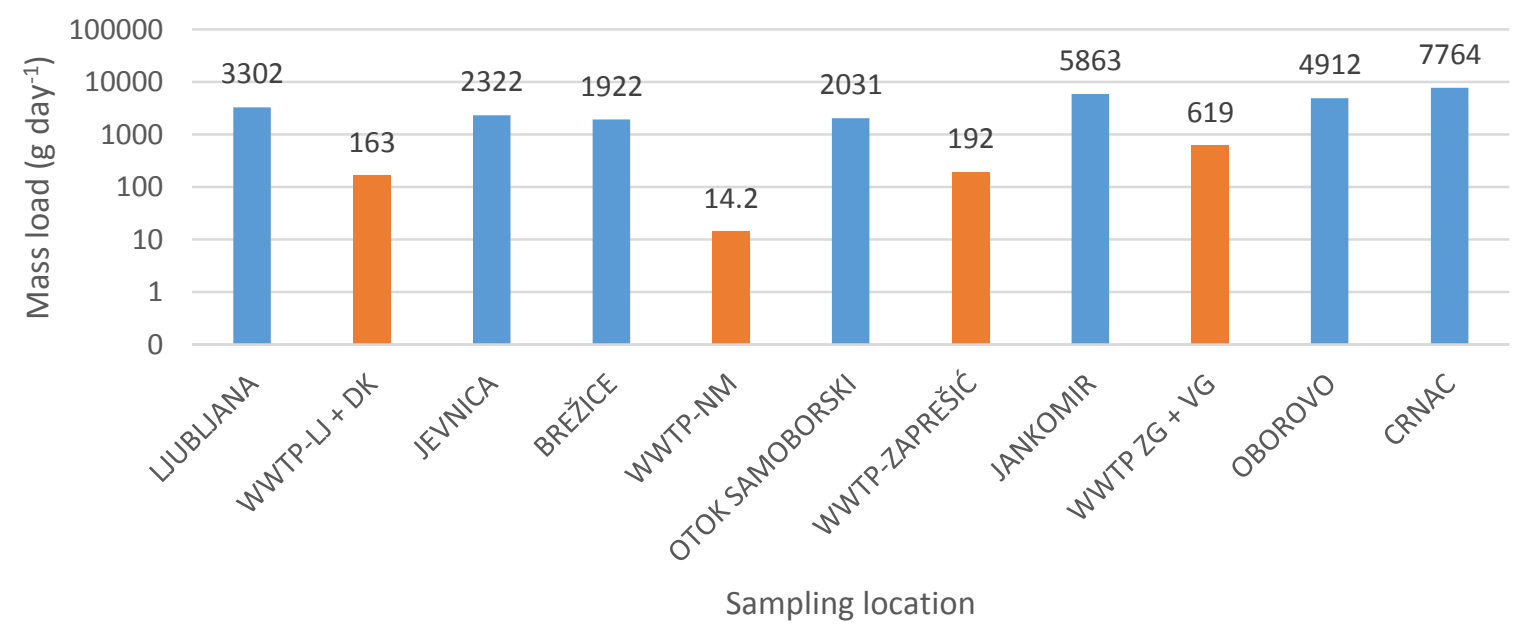

Figure 6: Total CEC mass loads at all sampling locations in May (A) and July (B). Sava river is marked in blue, whereas WWTP effluents are marked in orange.

\subsection{Environmental risk assessment}

An ERA was determined by establishing RQs using the average concentrations of CEC determined in SW (Table 7). Toxicity data (lowest values of EC/LC 50 or NOECs were taken for "worst-case scenario") were either taken from the literature or calculated using the ECOSAR software V2.0 (SI-VI). Only HM-BP, BPP and Be-PB represented a medium risk according to their average concentrations (Table 7). 
Table 7: Determined RQ values based on the average and highest CEC concentrations in SW samples.

\begin{tabular}{|c|c|c|}
\hline & $\mathbf{R Q _ { \text { aver. } }}$ & $\mathbf{R Q}_{\text {highest }}$ \\
\hline CAF & 0.00188 & 0.00922 \\
\hline BIS2 & 0.00530 & 0.00929 \\
\hline HM-BP & 0.289 & 1.13 \\
\hline $\mathrm{BPA}_{1}$ & 0.0117 & 0.0410 \\
\hline $\mathrm{BPA}_{2}$ & 0.00615 & 0.0215 \\
\hline BPCL2 & 0.000645 & 0.00152 \\
\hline $\mathrm{BPZ}$ & 0.0387 & 0.0753 \\
\hline BPS & 0.000164 & 0.000641 \\
\hline BPAP & 0.00228 & 0.00293 \\
\hline BPP & 0.120 & 0.120 \\
\hline MePB & 0.00235 & 0.0125 \\
\hline EtPB & 0.00111 & 0.00672 \\
\hline IB & 0.0280 & 0.159 \\
\hline MEC & $8.37 \mathrm{E}-05$ & $8.37 \mathrm{E}-05$ \\
\hline PrPB & 0.00560 & 0.0304 \\
\hline$N P$ & 0.00304 & 0.00780 \\
\hline $\mathrm{KP}$ & 0.000391 & 0.00338 \\
\hline Be-PB & 0.337 & 0.626 \\
\hline CBZ & 0.000623 & 0.00133 \\
\hline DF & 0.000237 & 0.000476 \\
\hline
\end{tabular}

345 The RQ values taking into account the highest determined concentrations revealed that HM346 BP (44.2 $\left.\mathrm{ng} \mathrm{L}^{-1}\right)$ in a sample Jevnica-1, which is a sample of Sava River, collected after WWTP- 
LJ and WWTP-DK discharges, represented a high environmental risk (SI-V). Interestingly, this compound was associated with a medium environmental risk also in a study by Česen et al.

349 (2018), who addressed the occurrence of CEC in various other Slovene SWs. In addition, BPP 350 (detected only on one occasion), IB and Be-PB posed a medium risk taking into account the highest determined concentrations in the samples from Brežice-1, Crnac-1 and Jankomir-2, respectively (Table 7). Further, RQs of all the samples that contained HM-BP, IB and Be-PB posed at least a medium risk to the environment since they contained either of these CEC (SI-VII). It is clear that high concentrations of CEC detected in water body like rivers do not necessarily pose a significant risk to the environment. However, one must take into account that mixture of various CEC occurs in the environment, hence, individually-derived calculations of RQ values might be misleading. Therefore, investigation of the toxicity of naturally occurring mixtures must be considered in future studies.

\section{CONCLUSIONS}

The occurrence of 48 CEC was assessed in Slovenian and Croatian WWTP effluents and in Sava River for the first time. In total, 23 and 19 CEC were above the LOQ in WW and SW, respectively, with CAF being the most abundant in both matrices. Several bisphenols (B and $E$ in $W W$ and $A P, C L 2, P$ and $Z$ in SW) were quantified for the first time in Europe. CEC mass loads from the studied Croatian WWTPs contributed more towards overall contamination of Sava River if compared to Slovene WWTPs. Levels of the UV-filter HM-BP represent a high risk in the Sava River collected after WWTP-L and WWTP-DK discharges, whereas other SW samples containing either HM-BP, IB or BePB pose a medium risk based on $R Q$ determination. The obtained data within this study can serve as a good basis for future monitoring studies that will cover the whole Sava River catchment, i.e. from its origins in Slovenian Alps until its confluence with the Danube River in Serbia. 
373 The authors wish to thank all WWTPs and Dr. David Kocman for their collaboration.

\section{FUNDING}

The authors acknowledge the projects L1-5457, J1-6744, L1-7544, J2-8162, J1-8147, N10047, the program groups P1-0143 and P-0230, which were financially supported by Slovenian Research Agency and the bilateral project BI-HR/16-17-025 also supported by Slovenian Research Agency and Croatian Ministry of Science. This work was supported by EC 7th Framework Programme Funding under Grant agreement no. 603629-ENV-2013-6.2.1Globaqua and MASSTWIN project that has received funding from the European Union's Horizon 2020 research and innovation programme under grant agreement no. 692241.

\section{REFERENCES}

Archer, E., Petrie, B., Kasprzyk-Hordern, B., Wolfaardt, G.M., 2017. The fate of pharmaceuticals and personal care products (PPCPs), endocrine disrupting contaminants (EDCs), metabolites and illicit drugs in a WWTW and environmental waters. Chemosphere 174, 437-446.

Bueno, M.J.M., Gomez, M.J., Herrera, S., Hernando, M.D., Agüera, A., Fernández-Alba, A.R., 2012. Occurrence and persistence of organic emerging contaminants and priority pollutants in five sewage treatment plants of Spain: Two years pilot survey monitoring. Environmental Pollution 164, 267-273. EU Decision 495/2015, Commission implementing Decision (EU) 2015/495 of 20 March 2015 establishing watch list of substances for Union-wide monitoring in the field of water policy pursuant to Directive 2008/105/EC of the European Parliament of the Council. Official Journal of European Union 78, 40-42.

Česen, M., Heath, D., Krivec, M., Košmrlj, J., Kosjek, T., Heath, E., 2018. Seasonal and spatial variations in the occurrence, mass loadings and removal of compounds of emerging concern in the Slovene aqueous environment and environmental risk assessment. Environmental Pollution 242, Part A, 143-154.

Gracia-Lor, E., Rousis, N.I., Zuccato, E., Bade, R., Baz-Lomba, J.A., Castrignanò, E., Causanilles, A., Hernández, F., Kasprzyk-Hordern, B., Kinyua, J., McCall, A.-K., van Nuijs, A.L.N., Plósz, B.G., Ramin, P., Ryu, Y., Santos, M.M., Thomas, K., de Voogt, P., Yang, Z., Castiglioni, S., 2017. Estimation of caffeine intake from analysis of caffeine metabolites in wastewater. Science of The Total Environment 609, $1582-1588$.

Loos, R., Carvalho, R., António, D.C., Comero, S., Locoro, G., Tavazzi, S., Paracchini, B., Ghiani, M., Lettieri, T., Blaha, L., Jarosova, B., Voorspoels, S., Servaes, K., Haglund, P., Fick, J., Lindberg, R.H., Schwesig, D., Gawlik, B.M., 2013. EU-wide monitoring survey on emerging polar organic contaminants in wastewater treatment plant effluents. Water Research 47, 6475-6487. Meffe, R., de Bustamante, I., 2014. Emerging organic contaminants in surface water and groundwater: A first overview of the situation in Italy. Science of The Total Environment 481, 280295.

Milačič, R., Zuliani, T., Vidmar, J., Oprčkal, P., Ščančar, J., 2017. Potentially toxic elements in water and sediments of the Sava River under extreme flow events. Science of The Total Environment 605606, 894-905. 
Osorio, V., Imbert-Bouchard, M., Zonja, B., Abad, J.-L., Pérez, S., Barceló, D., 2014. Simultaneous determination of diclofenac, its human metabolites and microbial nitration/nitrosation transformation products in wastewaters by liquid chromatography/quadrupole-linear ion trap mass spectrometry. Journal of Chromatography A 1347, 63-71.

Papageorgiou, M., Kosma, C., Lambropoulou, D., 2016. Seasonal occurrence, removal, mass loading and environmental risk assessment of 55 pharmaceuticals and personal care products in a municipal wastewater treatment plant in Central Greece. Science of The Total Environment 543, 547-569. Petrie, B., Barden, R., Kasprzyk-Hordern, B., 2015. A review on emerging contaminants in wastewaters and the environment: Current knowledge, understudied areas and recommendations for future monitoring. Water Research 72, 3-27.

Petrie, B., Youdan, J., Barden, R., Kasprzyk-Hordern, B., 2016. Multi-residue analysis of 90 emerging contaminants in liquid and solid environmental matrices by ultra-high-performance liquid chromatography tandem mass spectrometry. Journal of Chromatography A 1431, 64-78. Sauvé, S., Desrosiers, M., 2014. A review of what is an emerging contaminant. Chemistry Central Journal 8, 15-15.

Smital, T., Terzic, S., Loncar, J., Senta, I., Zaja, R., Popovic, M., Mikac, I., Tollefsen, K.E., Thomas, K.V., Ahel, M., 2013. Prioritisation of organic contaminants in a river basin using chemical analyses and bioassays. Environ Sci Pollut Res Int 20, 1384-1395.

Sousa, J.C.G., Ribeiro, A.R., Barbosa, M.O., Pereira, M.F.R., Silva, A.M.T., 2018. A review on environmental monitoring of water organic pollutants identified by EU guidelines. Journal of Hazardous Materials 344, 146-162.

Stipaničev, D., Dragun, Z., Repec, S., Rebok, K., Jordanova, M., 2017. Broad spectrum screening of 463 organic contaminants in rivers in Macedonia. Ecotoxicology and Environmental Safety 135, 48-59. Terzić, S., Senta, I., Ahel, M., Gros, M., Petrović, M., Barcelo, D., Müller, J., Knepper, T., Martí, I., Ventura, F., Jovančić, P., Jabučar, D., 2008. Occurrence and fate of emerging wastewater contaminants in Western Balkan Region. Science of The Total Environment 399, 66-77. Tousova, Z., Oswald, P., Slobodnik, J., Blaha, L., Muz, M., Hu, M., Brack, W., Krauss, M., Di Paolo, C., Tarcai, Z., Seiler, T.-B., Hollert, H., Koprivica, S., Ahel, M., Schollée, J.E., Hollender, J., Suter, M.J.F., Hidasi, A.O., Schirmer, K., Sonavane, M., Ait-Aissa, S., Creusot, N., Brion, F., Froment, J., Almeida, A.C., Thomas, K., Tollefsen, K.E., Tufi, S., Ouyang, X., Leonards, P., Lamoree, M., Torrens, V.O., Kolkman, A., Schriks, M., Spirhanzlova, P., Tindall, A., Schulze, T., 2017. European demonstration program on the effect-based and chemical identification and monitoring of organic pollutants in European surface waters. Science of The Total Environment 601-602, 1849-1868. Tran, N.H., Reinhard, M., Gin, K.Y.-H., 2018. Occurrence and fate of emerging contaminants in municipal wastewater treatment plants from different geographical regions-a review. Water Research 133, 182-207. 
Supplementary material for on-line publication only
Click here to download Supplementary material for on-line publication only: Supplementary_Sava River22062018.docx

Supplementary material for on-line publication only
Click here to download Supplementary material for on-line publication only: Supplementary_Sava River22062018.docx

(a) 